\title{
El ceremonial de la limpia de canales en Caspana
}

\author{
Ana Isabel Matus de la Parra
}

\section{INTRODUCCIÓN}

Es tradición de los pueblos andinos realizar la limpia de canales en forma comunitaria. El significado de este acontecimiento trasciende su quehacer funcional; de hecho puede ser considerado como una conductá simbólica de un pueblo.

Los motivos y objetivos de esta celcbración son los mismos en todo el mundo andino: Perú, Bolivia, el N.O. Argentino y el Norte de Chile. Aun cuando el principio es igual para todos, cada pueblo manteniene sus propios matices que resultan en un desarrollo histórico. cconómico, social y cultural diferente.

El objetivo de la limpia de canales es simple y permite que toda una comunidad trabaje, sacando fuera los escombros y desperdicios que se han ido acumulando durante el año, los que van impidiendo el paso normal del agua.

El motivo es más sutil debido a que implica una creencia y ésta es causa de que toda acción hecha durante la limpia de canales sea acompañada por ceremonias y varios rituales. Por consiguiente, todas estas acciones son dirigidas al elemento agua, clemento de vital importancia en la vida del hombre.

Para lograr lo señalado anteriormente fie imprescindible una descripción minuciosa de la limpia de canales, considerando la escasa literatura andina que existe sobre el tema.

En primer término, describiré el pueblo de Caspana en su contexto geográfico e histórico, para luego mencionar autores que se han ocupado del análisis de la limpia de canales en el mundo andino. 
Después haré una relación de los ocho días de trabajo comunitario y sus respectivos rituales.

\section{UBICACIÓN GEOGRÁFICA Y ANTECEDENTES HISTÓRICOS}

En uno de los afluentes del río Loa se ubica el pueblo de Caspana a $3.264 \mathrm{~m}$. s.n.m., en la II Región, provincia de El Loa, a 96 km al N.E. de la ciudad de Calama, Chile.

Esta zona es un gran valle longitudinal originado en el Terciario, el cual comprende el curso superior del río Loa hasta Calama.

La cuenca del Loa tuvo su origen en la falda oriental de los Andes, que entonces no eran tan altos como para impedir la pasada de los vientos húmedos. Posteriormente hubo un avanzado estado de erosión y gran cantidad de erupciones volcánicas. Toda la zona tiene un piso de relleno volcánico de la formación riolítica, el que ha sido erosionado con el pasar del tiempo, formando quebradas que bajan desde las cumbres volcánicas, dando origen a profundos cañones de muy poco ancho; uno de éstos ha sido formado por el río Caspana.

Según Ochsenius, el suelo es volcánico, y esto permite sólo una vegetación escasa, definida como xerófita del reino floral andino, básicamente compuesta por gramíneas, cojines espinosos y algunas comunidades de arbustos.

La fauna está compuesta por camélidos (llamas, vicuñas), roedores y vizcachas.

El primer asentamiento en Caspana se remonta a los 6.000 años antes del presente, con una concentración fuerte de población en los años $850 \mathrm{~d}$.C. En este período se construyó el pueblo viejo, donde se ubica la iglesia española. Considerando su lejanía de los centros establecidos por los españoles, el pueblo no ha cambiado sus estructuras de vida cultural y social; sin embargo, la construcción de una nueva iglesia católica y la visita anual del párroco de San Francisco de Chiu-Chiu, introdujeron un sincretismo entre el pensamiento indígena prehispánico y el de la religión católica.

Al iniciarse el desarrollo de la minería en la zona, los caspaneños se dedicaron a la comercialización de la llareta* en las salitreras y en las minas de cobre. Una vez que se introdujo la energía eléctrica, el consumo de la llareta disminuyó en tal forma que los lugareños tuvieron que cambiar la fuente de sus entradas por la siembra y ventas de hortalizas. A su vez, el pastoreo también sufrió un cambio; las vegas se fueron secando por la necesidad de agua de los nuevos centros urbanos en desarrollo, como 
Antofagasta, Calama y Tocopilla los que demandan en abundancia de este vital elemento.

Actualmente Caspana cuenta con 482 habitantes que se dedican a la agricultura y ganadería. La agricultura se desarrolla a lo largo de la quebrada de Caspana en 50 hectáreas de cultivo, que son la fuente principal de la actividad comercial. Éstas están construidas en terrazas en la ladera del barranco con melgas de $4 \mathrm{~m}$ por $4 \mathrm{~m}$, y atravesadas por canales de regadío que surgen del canal matriz de 14 kilómetros de largo, contados desde su fuente en las vegas de Cablor.

Los tipos de cultivo son variados, pudiéndose citar en la horticultura el cilantro, el perejil, el ajo, la lechuga, las habas, las papas; en la fruticultura la manzana, el damasco, la pera, las tunas, y en la floricultura las dalias, los gladiolos, los alelíes y los claveles.

Además hay que mencionar la alfalfa por su gran importancia como forrajera.

La ganadería se desarrolla en pequeña escala en los alrededores del pueblo, en lugares llamados estancias. Los lugareños poseen aproximadamente unas 500 cabezas de ganado, entre camélidos, ovejas, cabras y burros.

A partir de 1977 Caspana comienza un desarrollo fuerte en su infraestructura, con la construcción de una escuela fronteriza. Ésta posee una matrícula aproximada de 160 alumnos provenientes de los pueblos de Toconce, Cupo, Ayquina, Lasana y San Francisco de Chiu-Chiu.

Además cuenta con una posta, que es atendida por un practicante que cubre las necesidades de salud de los lugareños, y también de los que viven en pueblos vecinos.

La participación que en este pueblo mantienen sus comuneros se aprecia en diferentes entidades, como son la Junta de Vecinos, Centro de Madres, el Club Deportivo y la Acción Católica, sin perder en su estructura comunera tradiciones que aún conservan entre ellos.

Caspana no está ajeno, al igual que otros pueblos, a brindar un culto a sus antepasados. Es así como en la actualidad Caspana cuenta con un museo de 312 metros cuadrados, donde se puede apreciar el material arqueológico proveniente del mismo pueblo. Siendo Caspana un área de gran valor arqueológico, se encuentran varios asentamientos prehispánicos en un radio de $14 \mathrm{~km}$. A lo largo del río Caspana, en Cablor y Pila, se hallan los sitios más tempranos conocidos hasta ahora, los que datan de 3.000 años a.C. En la quebrada abajo, en el medio del río, está el pictoglifo quizá más grande en un solo panel. A cuatro kilómetros al N.O. del pueblo se encuentra un asentamiento minero, cuyo comienzo data de 800 años a.C. y a $100 \mathrm{~m}$ de éste hay un tambo y un santuario inca. En la quebrada Incahuasi por donde pasaba el camino del inca hacia San Pedro de Atacama, encontramos más sitios arqueológicos relacionados con actividades mineras. Siguiendo por la quebrada de Curte encontramos una pintura de camélidos de color rojo. A 
siete kilómetros del cementerio de Los Abuelos, en la quebrada de Talikuna. aparecen más de 55 sitios arqueológicos, entre los cuales sobresale una aldea con bodegas y habitaciones.

\section{INVESTIGACIONES SOBRE EL TEMA}

En el contexto andino, la limpia de canales ha sido estudiada por algunos antropólogos, entre ellos Tello, Isbell, Barthel, Mendoza, Délano, Serracino. Sin embargo, ellos no han descrito la limpia de canales en forma detallada y completa, lo que restringe su análisis en muchos aspectos. Por consiguiente, este trabajo cumple con el objetivo de hacer una descripción completa y a su vez explica los significados de los rituales y acciones que se van desarrollando durante la limpia de canales.

En la provincia de E] Loa la celebración de la limpia de canales se puede dividir en dos sectores:

- En el sector norte se sigue un calendario consecutivo para la celebración de esta fiesta. En Santiago de Río Grande comienza un jueves después del 25 de julio; sigue Caspana el jueves después del 16 de agosto, continuando el pueblo de Cupo, en la primera semana de septiembre $y$, finalmente, Toconce, el último jueves de septiembre.

- En cambio, en el sector sur la limpia de canales es celebrada en una fecha fija, el 24 de octubre, en el pueblo de Socaire.

- El resto de los pueblos, como Peine. Cámar, Talabre, Toconao y el poblado de San Pedro de Atacama no celebran estas fiestas, debido a que el Departamento de Riego del Ministerio de Obras Públicas tomó la tuición de los canales bajo su dirección, lo que sustituyó el trabajo comunitario, y, por consiguiente, se eliminó la fiesta.

La limpia de canales se presta para aplicar diferentes modelos propuestos por la Antropología. Los antropólogos utilizan modelos ecológicos, de parentesco, o de economía. Pero en este trabajo se ha utilizado el modelo de cognición, ya que, al parecer, ningún especialista en la materia lo ha aplicado.

En el estudio de la limpia de canales Serracino sugiere que el punto más relevante de ésta es su importancia en ilustrar la creencia andina misma, pero, sin embargo, no hace un análisis completo de la fiesta. Por lo tanto este trabajo se propone complementar el suyo, poniendo énfasis sobre rituales y ceremonias.

La metodología que se empleó en esta investigación consistió en la participación directa con los comuneros del pueblo de Caspana. Es así como en el añó 1984 fui observando muchos de los acontecimientos que ocurrían durante el transcurso de la fiesta. 
En el año 1985 mi trabajo consistió en una participación directa en lo que concierne al ritual.

En el año 1986 mi participación fue total, ya que acompañé de principio a fin a los comuneros en la realización del trabajo propio de la limpia del canal y su fiesta, poniendo énfasis en observar el rol de la mujer, al igual que el de los jóvenes, niños y ancianos; anotando detalles, a la vez dialogando con diferentes personas que visitan a los lugareños en esta ocasión. Ese año fue de una satisfacción plena, ya que en medio de tanto regocijo fui elegida por la comunidad de Caspana como una comunera más. Por lo tanto en este trabajo no sólo aporto un estudio etnológico, sino que dejo constancia de este aporte de integración en una comunidad andina.

La secuencia del ceremonial es la siguiente:

Miércoles,: . Ritual del huaqui.

Jueves : Limpia del canal matriz.

Sábado : La gran ceremonia. Término de la limpia del canal matriz.

Domingo : Agradecimiento en la iglesia. El alférez encargado ofrece la boda a la comunidad.

Lunes : Nuevamente el alférez ofrece la boda a la comunidad.

Martes : Limpia del canal de la quebrada chica, en el centro del pueblo.

Miércoles : Limpia del canal en el sector Quitor, a la entrada del pueblo. Jueves : Reunión general. Elección de la nueva directiva comunal para el trabajo de la limpia del canal del próximo año.

\section{RITUAL DEL HUAQUI}

Según varios ancianos del pueblo. el huaqui ocupa un lugar muy destacado en la limpia de canales, porque la realización de este ritual en forma completa les dará un buen resultado en la fiesta.

Huaqui es palabra quechua, que significa sagrado, general, motivo por el cual no es de exclusividad de la limpia de canales, sino que puede repetirse en varias actividades y ocasiones. No así la entrega de instrumentos tales como clarines, pitos, cachos, al igual que el látigo, elementos específicos de la limpia, como también la presencia de las purikamanas, el purikamani y los capitanes*.

La casa donde se celebra este ritual es de suma importancia, ya que la misma comunidad se preocupa que ésta sea conservada en su estructura original, no permitiendo a la familia que es propietaria que la venda, ni que por arreglos de sucesión pueda recibirse por herencia. Sólo puede ser usada para y por motivos rituales del pueblo. Esto hace, entonces, que la tradición

\footnotetext{
*Autoridades que guían el desarrollo del ceremonial.
} 
oral y la herencia sean aspectos importantes y de real trascendencia en la limpia de canales.

Esta casa muestra algunas características arquitectónicas que no presentan otras casas del pueblo. El techo tiene diferentes tipos de envigados de distintas alturas. Las vigas más altas pertenecen al centro y las más bajas declinan hacia los tímpanos o mojinetes llamados así por los mismos lugareños. Las piedras de su construcción no están canteadas ni labradas, teniendo las mismas características de una casa construida en un pueblo abandonado a 7 kilómetros al N.O. de Caspana, llamado Talikuna. Por consiguiente, esta casa indica una antigüedad de 900 años d.C., (Serracino, comunicación personal). La comprobación arqueológica confirma en parte la veracidad de los caspaneños sobre este particular.

Los oficiantes principales de esta ceremonia son las purikamanas y los mayores. Las purikamanas son dos mujeres ancianas, que han heredado su cargo, cargo que posee varias funciones.

1. Conservar año a año los instrumentos musicales: el pito y dos tambores (solvares), llamados así por los lugareños. Estos instrumentos tienen una significación sagrada.

2. Durante la ceremonia, entrega a los capitanes los instrumentos rituales de autoridad, como dos cachos y dos látigos. También entregan los clarines a los cantores.

3. Proveer la chicha, el vino, la harina y hojas de coca para el ritual del huaqui.

La funcionalidad y manufactura de algunos instrumentos tienen el siguiente significado:

La función a la cual es destinado el clarín es solamente para alegrar el trabajo en el inicio del almuerzo y en los descansos. La responsabilidad de conservar año a año los clarines la tiene una familia del pueblo, lo que viene por herencia. Este instrumento no tiene significado sagrado. Está hecho de una caña que se trae de Bolivia, forrada con lanas de diferentes colores.

El pito es usado por las mujeres cuando dan el saludo después del almuerzo del día sábado. Instrumento de madera que tiene esculpida una cara de hombre.

Los solvares tienen significación sagrada, ya que cumplen con la función específica de ser tocados en el baile del Chau-Chau. Son tambores de madera y cuero.

Los cachos simbolizan el poder y autoridad de los capitanes.

Los látigos son de uso exclusivo de los capitanes, ya que también simbolizan autoridad. Son dos trenzas de cuero de llamo. 
Por tradición, los mayores son considerados como los primeros que se asentaron en el pueblo. Debido a esto es que el ritual del huaqui para la limpia de canales es llevado a efecto en la casa de los mayores, porque se considera que el agua es una continuidad de herencia. Por lo tanto, el símbolo humano será también continuidad de las personas.

En cuanto a la distinción entre mayores y ancianos, los lugareños hacen notar una diferencia bien marcada; los mayores provienen de aquellas familias que se establecieron primero en el pueblo, mientras que los ancianos son todos los comuneros mayores de edad y los encargados de los rituales del pueblo.

El ritual del huaqui es celebrado el miércoles en la noche y se lleva a efecto en la casa de los mayores, que es de propiedad de Aurelia y Flora Anza. En esta ocasión se reúnen los mayores, los ancianos, los capitanes, los purikananas, el purikamani y junto a ellos la directiva de la Junta de Vecinos, además de otros lugareños que respetuosamente observan la ceremonia.

Este ritual se realiza en la dependencia principal de la casa, donde se encuentran asientos de piedra comúnmente llamados poyos, y en el centro dejan una mesa circular de madera para efectuar el ritual.

Antes de comenzar la ceremonia, los capitanes y la familia, encargada de guardar y a su vez de tocar los clarines, entregan sus instrumentos a las purikamanas.

Posteriormente ellas se preparan para dar inicio al ritual, llevando a la mesa dos cachos, dos látigos, dos clarines, una chuspa con hojas de coca, dos jarros vacíos, un jarro de vino, dos paños blancos, cada uno con dos tipos de harina, una blanca y otra negra. Todos estos elementos son preparados para que una de las purikamanas tome de un paño blanco un poco de harina negra (harina de quínoa), y con su mano izquierda la eche al jarro puesto también a su izquierda, accion muy significativa para todos, ya que con esto recuerdan a sus antepasados. Nuevamente la purikamana con su mano derecha, vuelve a tomar un poco de harina, pero esta vez es blanca (tradicionalmente hecha de maíz), y la deposita en el otro jarro vacío que se encuentra a su derecha. Después pasa a entregar los cachos y látigos a los respectivos capitanes; proporciona los clarines a los cantores y, por último, levanta las hojas de coca en señal de poder.

Una vez terminado el ritual, un anciano entendido en las tradiciones del pueblo pide permiso a los presentes para comenzar la ceremonia, diciendo: "Con su permiso señoras purikamanas". Toma un poco de harina negra y la deposita en el jarro que se encuentra a su izquierda, y reza para que todos los espíritus de los ancianos que construyeron los canales les ayuden en el trabajo que iniciarán el día siguiente.

Repiten el mismo ritual el presidente de la Junta de Vecinos y todos los demás asistentes. Una vez que todos han hecho sus ofrendas, la dueña de casa 
pone sobre un paño hojas de coca y le pasa un vaso de vino al anciano, y a los que están sentados a la mesa. Seguidamente, el anciano pide permiso vertiendo un poco de vino a la pacha-mama; toma algunas hojas de coca y las deposita en el jarro que se encuentra a su izquierda y dice: "En buena hora a las purikamanas, en buena hora a los capitanes, en buena hora al presidente y, por último, en buena hora a los mayores y ancianos". Después de estas repeticiones of rece el vaso de vino y las hojas de coca a todos los presentes, los que también repiten lo dicho por el anciano.

Avanzada la mañana, alrededor de las 4:00 hrs., aproximadamente, todos los oficiantes y asistentes se retiran de la casa, quedando solamente el más anciano, el cual toma los jarros con sus of rendas y haciéndose acompañar por un joven se va con dirección a la quebrada.

Una vez que llegan a la quebrada, el anciano eleva entre sus manos los jarros y vierte sus contenidos al vacío, invocando a los espíritus e implorando que esta limpia tenga un buen resultado para el año que está por comenzar. Con imploraciones y cantos del anciano se pone fin a la ceremonia ritual del huaqui.

Después de haberse realizado la ceremonia del ritual del huaqui, aproximadamente a las 14:00 hrs. del día jueves, se reúnen 53 comuneros de un total de 84 para participar en una reunión breve, con el objetivo de conocer las asignaciones que les serán entregadas. La cantidad de comuneros reunidos en esta ocasión varía año a año.

El lugar donde se lleva a cabo la reunión es en el canal matriz cerca del estanque, próximo a la escuela fronteriza del pueblo. Todos los comuneros que allí se encuentran forman un círculo dentro de él, y cada uno coloca en el suelo su botella de vino y sus chuspas con hojas de coca.

Esta ceremonia la preside el presidente de la Junta de Vecinos, anteriormente llamado el alcalde del pueblo, y la dirigen los capitanes ya designados. Éstos tienen un rol importante en la limpia de canales, ya que uno de ellos es responsable por las mujeres y el otro por los hombres.

Además, los capitanes hacen el llamado a la gente por intermedio de sus cuernos y ponen orden con el látigo, por si alguno desobedeciese o manifestara alguna falta de respeto.

El capitán responsable de los hombres pide permiso para hablar y dar comienzo a la ceremonia: "Con su permiso señores y compañeros, buenas tardes. Hoy jueves, 23 de agosto de 1984, siendo las 14:30 hrs., se da por iniciado, como es ya nuestra costumbre y tradición, el trabajo de la limpia de canales, y con el permiso de todos voy a dar las divisiones que corresponden". 
Estas divisiones a las que se refiere el capitán, son para dos grupos. Uno de ellos es destinado a limpiar el camino que llaman los perales y el otro grupo para hacer la limpieza del canal. Entre los comuneros y también participando de la reunión, se encuentran dos mujeres adultas solteras, que tienen la misión de servir el vino a los hombres en los descansos.

Una vez asignados los trabajos, los ancianos allí presentes sacan de las chuspas* hojas de coca, y piden a las mujeres que se les sirva un vaso de vino para brindar por el éxito del trabajo; depositan un poco de vino en el canal y esparcen las hojas de coca, y mirando el cerro que se encuentra frente a ellos, el Paniri, solicitan que el trabajo que hicieron los abuelos sirva para ellos, que siempre corra el agua por el canal, que la fiesta se desarrolle sin ningún incidente.

Terminadas las imploraciones los comuneros brindan por el éxito de la limpia. Los capitanes hacen sonar sus cuernos para dar comienzo al trabajo.

En la reunión de ese año se debatió un punto que tiene bastante importancia par entender la limpia de canales y la organización social y política del pueblo, y consideré de importancia la acotación de cada uno de los comuneros, para su posterior análisis.

Antes de empezar a tomar sus ubicaciones según lo dispuesto por el capitán un comunero que pertenece a la familia que tiene la responsabilidad de tocar y a su vez conservar los clarines, pidió permiso para hablar, a lo que el capitán accedió. El comunero dijo que quedaba un punto importante por tratar, lo que la asamblea aceptó.

Él se refirió específicamente a que su familia, la que año a año debe tocar los clarines, no seguiría con esta responsabilidad, y que para esta limpia no tendría la colaboración de los suyos para tocar este instrumento. Intervino el presidente de la Junta de Vecinos y propuso que por esta fiesta fuesen ellos mismos los que buscaran a otros de su familia que los represente pero que cuando se hiciera la reunión de planificación general, al término de la limpia de canales para el próximo año, este asunto delicado se tratara en forma correcta, debido a que la responsabilidad de conservar y tocar los clarines es hereditaria, y no puede en esta ocasión ser tratado en forma liviana, sino que en este caso sea conversada y acordada unánimemente en asamblea general.

Entre los integrantes de la asamblea se produjo una polémica y el comunero de la familia de los clarines insistió en no seguir con el cargo, debido a que él y su familia generalmente están ausentes del pueblo, por motivos de trabajo. Algunos comuneros opinaron que la solución del problema podría ser semejante a la apertura del canal, es decir, que el comunero encargado de abrir la contrapuerta del canal es ya demasiado viejo y su edad no le permite llegar hasta el final de la bocatoma para lanzar el agua, y 
sugirieron a la asamblea pasar el cargo al hijo mayor; a lo que nuevamente el comunero encargado de los clarines objetó dicha sugerencia, ya que su hijo no se encuentra siempre en el pueblo por estar trabajando fuera de él. Entonces la asamblea acordó dejar este cargo al hermano del padre, que es la relación más cercana de parentesco.

Siguiendo con el problema que se les ha presentado, el capitán opinó que nada tenía que ver el asunto de los clarines con la apertura del canal, a lo que el presidente de la Junta de Vecinos insistió que la familia de los clarines debía buscar un familiar que continúe con esta tradición, y que el hecho de dejar de guardar y tocar estos instrumentos se debería decidir en la asamblea general. Volvió la polémica entre los comuneros y el comunero encargado de tocar los clarines. Los comuneros, al igual que el presidente de la Junta de Vecinos, reiteraron que por nada debería perderse la tradición dejada por sus antepasados en la limpia de canales. Secamente, el capitán intervino diciendo que bastaba de discusiones, y que lo importante era que esta fiesta fuese realizada en buena forma y sería mejor que se lo responsabilizara a él de buscar a alguien para que en esta oportunidad se preocupara de los clarines, y que posteriormente la familia encargada de éstos deberá presentar su caso a la asamblea general. Los capitanes hicieron sonar los cuernos para dar por finalizada la reunión y dar paso al inicio del trabajo.

Todos los comuneros allí presentes empezaron a formar grupos, con sus palas, sus botellas de vino, sus chuspas con hojas de coca y se dividen poniéndose en fila para ser guiados por el capitán, que no deja de hacer sonar su cuerno. El grupo al que le tocó limpiar el camino va despejando éste con sus palas y sacando todo tipo de basura, para dejar expedito el paso para el día sábado, el que es de gran importancia para la comunidad. Siguen limpiando hasta llegar al lugar de descanso, que es a unos $200 \mathrm{~m}$ aproximadamente del canal matriz.

Entre tanto el otro grupo va por dentro del canal, sacando con sus palas la maleza, los arbustos chicos y piedras que se han ido acumulando durante el año, y mientras van pasando frente a una propiedad de alguno de ellos, el comunero propietario voluntariamente les invita a participar de un brindis. Entonces el grupo se detiene y colocan sus chuspas en común. Después de este alto siguen la limpieza del canal hasta llegar al lugar de descanso, donde se reúnen nuevamente con el otro grupo. Mientras van dejando sus implementos de trabajo, ponen sus chuspas y las botellas de vino en conjunto, y las mujeres encargadas les van sirviendo mientras que los hombres conversan y coquean. Los capitanes tocan sus cuernos en señal de orden e informan a todos la planificación del trabajo que se efectuará el día siguiente. Con atención escuchan lo que el capitán determina. Éste separa a un grupo de seis personas las que deberán ir al lugar de la merienda para el día sábado, para que arreglen las piedras que servirán de asiento, y que se preocupen del orden del lugar. También debe haber planificacion para el momento del almuerzo, 
lo que todos aceptan. Se sugiere el nombramiento de un capataz y que éste, a su vez, nombre a sus colaboradores para ejecutar el trabajo. Todos aceptan. La tarea consiste en que los hombres encargados deberán preocuparse que a todos se les sirva el almuerzo, comuneros y visitas, y a la vez que todos compartan los agradecimientos, y que si en esta oportunidad los acompañara alguna autoridad de Calama, sea ella bien recibida.

Para la merienda se propone a un comunero que ayude a los capitanes a velar por el orden. El comunero elegido no acepta el cargo, debido a que ya tiene el compromiso de atender a la gente a la llegada del almuerzo. Esta negativa es aceptada por la asamblea y entonces se sugiere a otro comunero, y éste también rechaza el cargo por encontrarse ocupado con los preparativos del almuerzo, para que esté a la hora fijada. La asamblea acota que debe haber espíritu de cooperación para que la fiesta se desarrolle de buena manera, pero los capitanes insisten en tener a alguien que les ayude con el orden y a la vez puedan reemplazarlos mientras ellos comen.

El capitán pide voluntarios. Se ofrece uno y éste es rechazado por encontrarse ebrio. Se ofrece otro y es aceptado por todos. Al mismo tiempo se le pide que busque a cinco comuneros para que le ayuden con el trabajo que se les asignará. El capitán "canta" (dice los nombres en voz alta a la asamblea) y nadie lo objeta. Después se elige al capataz para organizar el trabajo de los canales. Se nombra a uno de ellos y éste no acepta para dar lugar a que otros participen en los trabajos asignados por el capitán.

La asamblea sugiere a otro comunero. Éste acepta y a su vez elige a diez colaboradores. Se "cantan" sus nombres y cada uno de ellos acepta. Los capitanes vuelven a tocar sus cuernos para dar por finalizada la reunión. Cada comunero se preocupa de sus implementos y emprenden el regreso a sus hogares, para encontrarse nuevamente a las 7:00 hrs. del día siguiente.

Mientras que retornan a sus hogares, muchos en el pueblo tienen sus casas preparadas con ramadas y los dueños de éstas ofrecen a los comuneros vino y comida.

Alrededor de las 7:00 hrs. del día viernes, los capitanes van llamando por el pueblo con el sonido de sus cuernos, para que nuevamente los comuneros se reúnan en el lugar de descanso del día anterior. Una vez reunidos, la asamblea toma acuerdos y se especifican las divisiones de los grupos que seguirán limpiando el canal y preparando la mesa para el almuerzo.

Al finalizar los trabajos que fueron asignados, conjuntamente con limpiar el canal y el camino, los comuneros regresan al pueblo a eso de las 17:00 hrs y todos van participando en las ramadas. Van de casa en casa y los dueños de éstas los agasajan con el cariño, ofreciéndoles vino o chicha y en algunas casas les dan un plato de comida: como es tradicional, un caldo de llamo. Los capitanes, aparte de ir acompañados de todos por las ramadas, van observando quiénes invitan y quiénes no, y anotan este detalle para que en la reunión de evaluación final se dé cuenta de quiénes del pueblo participan junto a 
ellos. A los que no cooperan se les impondrá un castigo, el que consiste en trabajos comunales, como por ejemplo, arreglar una parte del camino dentro del pueblo, que ha sido dañado por catástrofes naturales; trabajos de la Junta de Vecinos, trabajos en la iglesia; en general, que sean en beneficio del pueblo, o por último, pagar una multa equivalente a lo que ellos no han contribuido. Por este motivo, todos los que son comuneros en el pueblo tratan de cooperar y participar dentro de sus posibilidades, para que la fiesta de la limpia de canales tenga un buen resultado.

En la ley indígena nos encontramos con el sistema de la reciprocidad, es decir, ellos reciben el trabajo de las personas y deben pagarlo con lo que ellos llaman el cariño. No hacer esta acción equivale a despreciar sus tradiciones.

En este caso específico no colaborar con los comuneros que hacen el trabajo de la limpia del canal pasa a ser una falta grave frente a la comunidad, ya que se quiebra el sistema económico del pueblo, y debido a esto es que los capitanes toman las medidas necesarias para que todos puedan colaborar y a su vez cumplir con sus obligaciones.

Entre tanto en el pueblo se va advirtiendo el sentido que lo lugareños dan a la limpia, porque son visitados por personas que provienen de otros pueblos vecinos, como: Toconce, Cupo, Ayquina, y Chiu-Chiu. La mayoría de estas personas no posee tierra en Caspana, pero sí casi todos tienen familiares en el pueblo, con los cuales se reúnen y ayudan para la fiesta, de tal manera que cuando los caspaneños los visiten en sus pueblos, puedan sentirse integrados en sus fiestas. En cuanto a las visitas de Calama, la mayoría de éstas son caspaneños, pero por motivos de trabajo han tenido que emigrar al sector urbano, y esto en parte tiene su lado negativo, ya que cada vez más son ellos mismos los que muchas veces objetan a la comunidad caspaneña dar a conocer sus tradiciones, porque piensan que en Calama van a ser tratados como indígenas.

El lado pintoresco lo colocan las casas con sus hornos humeantes, lo que hace atractivo al visitante, ya que se sienten los olores a comida, y por ende se prepara el ánimo para la llegada del día sábado, el cual todos esperan con ansias, para presenciar la culminación del trabajo de la limpia de canales.

Al llegar la madrugada del día sábado, alrededor de las 5:00 hrs, los capitanes, por lapsos de 15 minutos, empiezan a llamar a los comuneros. Un capitán toca su cuerno en la última casa de la quebrada, mientras que el otro recorre las angostas callejuelas del pueblo viejo con el sonido propio de su cuerno.

Alrededor de las 7:00 hrs, los capitanes nuevamente van llamando con el sonido de sus cuernos a los hombres, y apurando a las mujeres, jóvenes y niños.

Al emprender la caminata aproximadamente a las 8:15 hrs., el capitán responsable por los hombres se asegura que ellos terminen de limpiar la parte del canal que llega hasta la mesa del almuerzo, y el capitán responsable por 
las mujeres se preocupa que éstas no tengan problemas con sus cargas. Algunos hombres, que son visitas de los comuneros, ayudan a las mujeres más ancianas. Las cargas generalmente consisten en ollas, ramas secas, y aguayos (mantas y cubiertos para los alimentos).

El recorrido es de 14 kilómetros, los que son devididos en dos tramos: los primeros 7 kilómetros hasta la mesa del almuerzo, y los 7 siguientes hasta la bocatoma del canal.

Aproximadamente a las 9:30 hrs. ya se encuentran en su totalidad las mujeres, las que se instalan en espacios reducidos debido a lo accidentado de la huella y barrancoso del terreno, en plena faena para el almuerzo. Las mujeres calientan sus comidas en ollas nuevas que compran para esta ocasión. El almuerzo ha sido preparado temprano, así que ellas solamente lo calientan y esperan a que sus hombres lleguen. Se puede observar a cada mujer muy afanada para ofrecerle a su hombre una rica comida, para que éste quede satisfecho y pueda seguir limpiando el canal con agrado.

Entre tanto, dos jovencitas preparan un balde con agua y un paño blanco, para que cuando lleguen los hombres al lugar de descanso puedan lavarse las manos y quedar en espera para almorzar.

A las 10:15 hrs. se escucha al capitán que viene con los hombres tocando el cuerno, en señal de que su grupo está llegando al lugar de descanso, el cual se ubica a unos 9 metros de los fogones de las mujeres. Las jovencitas se preparan para recibirlos con sus implementos de aseo. Una vez que éstos se instalan, se lavan las manos y se van sentando en espera de que las mujeres adultas les vayan pasando un váso de vino, y uno por uno empiezan a brindar y saludar de la siguiente manera: "Que Dios se lo pai" al purikamani, que Dios se lo pai a los capitanes, que Dios se lo pai a los alféreces, que Dios se lo pai al presidente".

Mientras que ellos dan los saludos, el capitán responsable por las nujeres va invitando a las visitas (mujeres) a participar con los hombres de los agradecimientos. Al llegar éstas, el capitán las ubica a uná distancia aproximada de 4 metros de los hombres y enfrente de ellas un paño blanco, lo extiende y coloca hojas de coca, les ofrece un pequeño vaso de vino, para que brinden por el buen ánimo y comportamiento de todos. Las visitas en esta ocasión provienen de los pueblos de Toconce, Cupo, Chiu-Chiu y de la ciudad de Calama. Las mujeres dan el saludo a los hombres diciendo: "Buenos días. señores". Vierten un poco de vino sobre la pacha-mama y luego brindan.

Terminados los saludos, nuevamente el capitán se dirige hasta donde se encuentran las mujeres de los comuneros preparando el almuerzo, y las invita para que vayan a dar el saludo de la mañana a sus hombres. Ellos, al verlas 
venir, se paran y escuchan con atención sus saludos "Buenos días señores" y ellos les responden "Buenos días señoras". Posteriormente ellas vuelven a sus faenas.

Entre tanto, en la mesa del almuerzo, dos ancianos, los que por su avanzada edad no participan de la limpieza del canal, cumplen la función de colocar al final de la mesa un mantel grande, con el cariño que la comunidad Caspaneña of rece a las visitas y forasteros.

El lugar donde se almuerza tiene asientos de piedra en forma rectangular y cuatro perales, los que cobijan a las autoridades caspaneñas. El terreno es angosto por la misma conformación de la quebrada.

Media hora más tarde, los hombres empiezan a ubicarse en la mesa por orden de jerarquía de la siguiente manera: al centro se sienta el presidente de la Junta de Vecinos, los ancianos, el purikamani, los alféreces, el comunero encargado de los oficios religiosos, los demás comuneros se ubican por herencia de sus antepasados y finalmente las visitas al final de la mesa.

Una vez que todos se han hubicado, las mujeres empiezan a llevar a sus hombres un mantel blanco laboriosamente bordado con rosas de colores, el que se encuentra muy bien envuelto. Éste se abrirá una vez que sean bendecidos los alimentos. También les dejan una botella de vino, una de bebida y otra de chicha de maíz.

Uno de los capitanes pide orden para que el comunero encargado de los oficios religiosos del pueblo bendiga los alimentos. Todos se ponen de pie y escuchan la oración. Terminada ésta, toman asiento y empiezan a abrir sus manteles. Es el momento de apreciar un despliegue de alimentos, como tarros de duraznos, pan amasado, huevos duros, costillas de llamo asadas, pisangallas (palomitas de maíz), agregándose todo el orgulllo que cada uno siente por ser apreciado por su mujer.

Al final de la mesa se observa a los ancianos abrir el mantel dispuesto para las visitas. Éste también tiene un surtido de comida, como pisangallas, pan amasado, costillas de llamo asadas, empanadas, queques. Mientras que los ancianos ofrecen a las visitas el cariño, éstas quedan a la espera del almuerzo que los lugareños les brindan con amabilidad.

En pleno almuerzo, los capitanes son reemplazados por jóvenes mensajeros, los que cumplen con la función específica de llevar obsequios a las visitas femeninas, como un vaso de chicha o vino generalmente arreglado con duraznos, empanadas, en fin, todo lo que ellos consideren de agrado para ellas, lo que muchas veces es acompañado de piropos. Entonces, aparte de saborear el apetitoso almuerzo, éste se convierte en un ir y venir de presentes, lo que nosotras las mujeres aceptamos de muy buen agrado.

El almuerzo consiste en un plato de caldo de carne y como plato de fondo, arroz con picante de pollo o de conejo.

Terminado éste, los capitanes hacen sonar sus cuernos, para pedir orden y silencio a los presentes, para que se hagan los agradecimientos. Turnándo- 
se, los capitanes dicen: "Que Dios se lo pai, purikamani, que Dios se lo pai, compañía y compañeros". Vuelven a tocar sus cuernos para que todos agradezcan nuevamente, lo que hacen diciendo: "Con su permiso señores, Dios se lo pai", y todos repiten: "Dios se lo pai". En ese momento las mujeres de los comuneros pasan a sus hombres vasos con ulpo (harina con vino o chicha), para que ellos levanten sus vasos y griten al unísono: "Dios se lo pai, señores, Dios se lo pai, compañeros". Al término de estas invocatorias, toman una rama seca, revuelven el ulpo y juntos se lo depositan a la pacha-mama, y vuelven a tomar asiento.

El capitán responsable de los hombres toca su cuerno para que todos los comuneros digan en voz alta: "Que Dios se lo pai, señoras y señores, Dios se lo pai, purikamani, Dios se lo pai, señores capitanes". En este instante de la ceremonia los comuneros se van parando para formar una fila, teniendo a su capitán delante de ellos. Respetuosamente, frente a los mayores y ancianos del pueblo, el capitán empieza a pasar uno a uno su cuerno, para que éstos le saquen sonido. El comunero lo toma y dice en voz alta: "Que Dios se lo pai", y hace sonar el cuerno, y así sucesivamente hasta llegar al último de la fila.

Mientras que esto ocurre, el capitán encargado de las mujeres, empieza a prepararlas para que ellas, al igual que los hombres, formen una fila.

Una vez que los comuneros terminan, el capitán de las mujeres las alinea y al igual que los hombres ellas también se ubican al frente de los mayores y ancianos, y su capitán les pasa el pito una a una, y repiten la misma invocación de los hombres: "Dios se lo pai", y sacan sonido al pito. Algunas de ellas se arrodillan a un lado de la fila en señal de agradecimiento a Dios, por ser bendecidas de tener el agua para sus cultivos, y a la pacha-mama por brindarle su generosa fertilidad.

Al término de este acto, el capitán pide orden para que el ministro católico pueda hacer la ceremonia religiosa, la que comienza con un canto:

"Demos gracias al Señor, aleluya,

por el pan que hoy nos dio, aleluya,

demos gracias al Señor, aleluya,

por el pan y la amistad".

Además, pide que todos recen en voz alta tres Padrenuestros y un Dios te Salve María, y pidan por la bendición de las almas. Terminados los rezos, el más anciano del pueblo canta El Alabado, canto medieval de la Iglesia Católica, seguido en los estribillos por los comuneros.

Aproximadamente a las 13:20 hrs. se finaliza esta ceremonia, y todos se preparan para terminar los últimos 7 kilómetros. Los comuneros toman sus implementos. forman una fila y siguen al capitán que no deja de hacer sonar su cuerno para darles ánimo de terminar la limpieza del canal. Éstos van sacando escombros, ramas secas y barro acumulado durante el año, haciendo 
sus descansos cada 150 metros, hasta llegar a la bocatoma del canal. Mientras que los niños, jóvenes y mujeres encabezan la larga fila por la estrecha y barrancosa quebrada.

Antes de llegar a la bocatoma se encuentra un estanque grande, el que empezará a llenarse una vez que sea lanzada el agua por el canal.

Después de la larga caminata por la quebrada. se llega a una vega donde el curso del río Caspana tiene su parte más ancha y alta, aplanándose el terreno, pasando el río por una de sus orillas y teniendo una hondonada entre medio de dos cerros.

Una vez que las mujeres, al igual que los jóvenes y niños, llegan a este lugar, van acomodando sus cargas para empezar a preparar los fogones para la merienda. Los fogones se componen de tres piedras puestas en forma circular, lo que hace que arbustos como la rica-rica* y el pingo-pingo ${ }^{*}$ 水 propios de la precordillera, les den el calor suficiente para la preparación de sus alimentos. Los niños en esta oportunidad tienen una participación activa, ya que sus madres los envían a buscar leña para los fogones. Las jovencitas se acercan al río a lavar los platos que quedaron del almuerzo, mientras que las mujeres adultas se afanan cocinando en sus espacios destinados para esta labor. Es el momento cuando se puede apreciar el humear de los fogones, el susurrar de las mujeres, la buena disposición de las jovencitas para ayudar a sus madres y el juguetear de los niños en las aguas del río.

Mientras que esto va aconteciendo, los dos ancianos que anteriormente fueron los encargados de poner el mantel envuelto con comida. repiten este quehacer para agasajar a las visitas.

Dos jóvenes que se encuentran sobre una piedra grande empiezan a tocar los clarines en señal de que están llegando los hombres del largo recorrido de los últimos 7 kilómetros. Estos jóvenes son designados por el capitán. Las jovencitas se preparan con sus baldes con agua y su paño, para que cuando lleguen los hombres puedan lavar sus manos y quedar en espera para la merienda.

A la distancia se escucha el sonido del cuemo de uno de los capitanes. lo que permite avisar a las mujeres que los hombres están llegando. Inmediatamente comienzan los preparativos para su recibimiento. Una vez que llegan, se asean las manos y empiezan a distribuirse a lo largo de la mesa, en el mismo orden de jerarquía que tuvieron durante el almuerzo. Cada mujer vuelve a colocarle a su hombre sus manteles bordados, su botella de vino o chicha y su bebida. Mientras esperan, todos conversan y coquean***, ya que ha sido una larga jornada de trabajo que está pronto a finalizar. A los

\footnotetext{
*Verbena orígenes.

$*$ Ephedra andina.

* Consumen coca
} 
hombres se les ve más relajados, satisfechos de haber podido otro año más trabajar en la ardua tarea de limpiar el canal.

Los capitanes, junto a los jóvenes, van acomodando a todos aquellos que no alcanzaron a sentarse a la mesa y los ubican en una de las terrazas del lugar. Una vez que todos se han ubicado, los capitanes tocan los cuernos en señal de la bendición de los alimentos. Todos se ponen de pie y el ministro católico hace la ceremonia de agradecimiento. Una vez bendecidos éstos, las mujeres empiezan a servir no dejando de lado a las visitas presentes. La merienda es muy similar al alnuerzo, sólo que esta vez tiene el sabor de frescura por haber sido cocinado momentos antes de servirse. Nuevamente ofrecen un plato de caldo de llamo con fideos, un pedazo de zapallo, dos papas cortadas, un pedazo de carne, todo espolvoreado con perejil picado, y como plato de fondo, arroz con carne picada, acompañado de vino o bebida.

Mientras que las mujeres van sirviendo a sus hombres, los ancianos abren el mantel para que las visitas y forasteros puedan servirse lo que ellos les ofrecen, esperando su turno para merendar.

Una vez que todos terminan de comer los capitanes empiezan a apurar a los presentes, tocando repetidamente sus cuernos, ya que pronto el sol bajará y aún queda la parte más importante del ceremonial de la limpia.

Las mujeres rápidamente se preocupan de tener los vasos con alpo, esta vez de harina con vino y hojas de coca, para que cuando sea lanzada el agua, ellas y sus hombres puedan vertirlo en el canal. La creencia que los lugareños tienen de mezclar estos elementos es, como ellos dicen, "para soltar el agua"; en otras palabras, para que el caudal del canal aumente.

El ministro católico pide la atención de los presentes, para que junto a él todos agradezcan a Dios. Respetuosamente lo escuchan y luego cantan:

"Demos gracias al Señor, aleluya.

por el pan que hoy nos dio, aleluya;

demos gracias al Señor, aleluya.

por el pan y la amistad. aleluya".

Al igual que en el almuerzo, rezan tres Padrenuestros, invocan a la Virgen María, rezando el Dios te salve, Maria, y agradecen a Dios por mantener vivas sus tradiciones y costumbres que les legaron sus antepasados. Nuevamente el más anciano canta El Alabado, seguido en los estribillos por los comuneros.

Terminado el canto, el ministro habla a los presentes: "En esta ocasión en que todos estamos agradeciendo a Dios, una vez más agradezcamos al Padre que creó la tierra donde todos nos encontramos", y todos en voz alta dicen: "Te agradecemos nuestro Dios, gracias, gracias". Lo repiten y el ministro dice: "Que así sea, amén".

Finalizada la ceremonia religiosa, los comuneros se reúnen con sus familias, para dirigirse a la orilla del canal, mientras van diciendo: "Que Dios 
se lo pai, señores capitanes, que Dios se lo pai, purikamani, que Dios se lo pai, alféreces, que Dios se lo pai, visitas y compañía". Los capitanes tocan sus cuernos dando la señal que luego será lanzada el agua.

En este lugar de la bocatoma el canal es proveído de las aguas de la vertiente del Cablor y el Coyer, que al unirse pasan a formar el río Caspana, designado así por los mismos lugareños.

Los comuneros se distribuyen a lo largo del canal, de manera muy similar a como lo hacen en la mesa del almuerzo y en la merienda, es decir, otra vez se impone la jerarquía; al comienzo lo hace el presidente de la Junta de Vecinos, seguido de los mayores y ancianos, a éstos los siguen los capitanes y el ministro del pueblo, terminando con los alféreces y el resto de los presentes. Todos con sus vasos con ulpo o vasos con vino o chicha, además de hojas de coca, y esperan que los capitanes toquen sus cuernos en señal de dar paso al más anciano para que entone un canto primitivo el que va diciendo algo así como "Chau Sana Chaina Kenkentu", y solamente otros ancianos lo ayudan en su canto, que tiene tres estrofas más, pero es imposible de captar lo que expresan.

Cuando el anciano termina el canto, el purikamani abre la compuerta del canal, y es entonces cuando todos, hombres, mujeres, jóvenes y ancianos, van vertiendo sus vasos con ulpo y esparciendo en el correr del agua las hojas de coca. En ese instante los capitanes y los clarinistas tocan y tocan sus instrumentos. Todos se abrazan, se piden perdón por las faltas cometidas, algunos lioran y cantan en señal de alegría, ya que para ellos un nuevo año ha comenzado, según el concepto indígena de que el año comienza con el inicio de las actividades agrícolas.

La voz purikamani está formada por dos palabras: puri significa agua en cunza, y kamani, poseedor, en aymara. Purikamani es una palabra que necesita una explicación filológica. Culturalmente tiene un uso simbólico, es decir, la persona que es purikamani no es poseedor real del agua, sino que representa los espíritus, los que son verdaderos poseedores del agua.

El purikamani cumple con la función específica de abrir la compuerta del canal, cargo que se hereda a través de una familia, la familia de los Paniri. Paniri viene del cerro que lleva su nombre y éste se encuentra al frente de Caspana. En su cumbre hay dos lagunas, teniendo la forma de macho y hembra, lo que lo hace bisexual. Según las tradiciones todos los cerros son machos y hembras y cuando se ponen el sombrero (las nubes), cae la lluvia. Por lo tanto el origen de los cerros y el cerro mismo están personificados en un hombre, el que lleva su apellido, como lo es en este caso del purikamani, quien abre la compuerta, simbolizando la acción que hace el cerro al dejar caer la lluvia.

Terminada la ceremonia de soltar el agua, aproximadamente a las 18:00 hrs., las mujeres vuelven por sus cargas, las que son llevadas sobre sus espaldas. Las jovencitas y niños también ayudan en esta faena, mientras que 
los hombres se preocupan de sus implementos de trabajo. Una vez que todos están listos, los capitanes tocan sus cuemos para dar la partida hacia el pueblo. Es así como comienza nuevamente la larga peregrinación por el borde de la quebrada.

Los capitanes, junto a dos mujeres ancianas, son los últimos en dejar el lugar. Esperando que todos se hayan retirado, ellos se van por la orilla del canal vertiendo vasos con ulpo y echando en el agua hojas de coca. Cada ciertos tramos descansan y los capitanes tocan sus cuernos, hasta llegar al canal matriz cerca del pueblo. Esta tarea la finalizan alrededor de las 21:30 hrs., y se sienten muy regocijados por haber cumplido un año más con estos rituales en forma completa ya que así, según ellos, tendrán el agua suficiente para sus cultivos.

Una vez que todos han llegado al pueblo, se dirigen a la iglesia, para dar los agradecimientos a Dios por el trabajo realizado. Pero los ancianos, el purikamani y los capitanes pasan por la casa de los mayores, casa donde fue realizado el ritual del huaqui, para sacar dos tambores pequeños, los solvares, para dar inicio a la fiesta.

Es importante destacar que se nota una diferencia entre el trabajo y la fiesta. El primero dura los días miércoles, jueves, viernes y sábado, hasta el momento de terminar la limpieza que corresponde al tramo final de los 7 kilómetros, y cuando lanzan el agua comienza la fiesta.

Terminada la ceremonia en la iglesia, se reúnen en la plaza para participar en una luminaria, fogata hecha con ramas de rica-rica. Esta luminaria la realizan en el centro de la plaza, toman vino caliente y bailan el tradicional chau-chau. Para su ejecución los comuneros forman un círculo, tomándose de las manos y moviéndolas de atrás hacia adelante, dando vueltas circulares. Los instrumentos musicales que se usan son solvares, clarines y cachos. El texto del que aquí se incluye es una transcripción de la versión entregada por un caspaneño, Julián Colamar. El significado de este texto lo ignoran los investigadores y ni siquiera lo conocen los mismos caspaneños; sin embargo, se sabe que el chat-chau es el sonido del agua corriendo por el canal y golpeando contra las piedras. (Serracino 1985, 399-410).

En la mañana del día domingo la mayoría de los lugareños van a la iglesia a escuchar la misa, la que termina aproximadamente a las 12:00 hrs. Posteriormente bajan a la plaza y nuevamente bailan el chau-chau.

En tanto, en la sede comunal, el alférez que tiene a cargo la responsabilidad de la boda, esto es el almuerzo de fiesta comunitario, junto a su familia, va preparando el recinto para atender de buena manera a toda la gente del pueblo. En estos almuerzos los encargados arreglan los mesones de manera muy especial, ya que en el centro de éstos les van poniendo hileras de pisangallas y pan amasado. El almuerzo consiste en un primer plato de caldo de llama, que es acompañado de papas, zanahorias, fideos y verdura picada, 
Kiti asas kutunas/kutunas yogomas kiti asas lantimas/lantimas yogomas ayaqgkhas chelayires/loyyak ninax/ ayaqgkhas sayares/kebusolar/keben... (se repite)

Nunas lantimas kirinas ganas cheponas ejehuntas/ salias/ kayqnas (tres veces dan vuelta)

Jugay lampabaya/ cheve cheve lampabaya chebe chebe lampabaya

las suya lampabaya

aya pini rezo rezo

pinchulen kayta... (se repite)

Kani kani labi kayta chinin chono

kaliten kaliten a los kita mendocita.

Kiluti kiluti kante chebe silunta achayunta lunkalum kalum kente kente kiryaes imas imas lu ta setas kaslabanka

Los abainakas konte gibt kente lucho sunay sintala inber sisays lo toko chayna en toloyto chayunta chayunta.

Tokagones patay mana salimanos ayigante ayigante sayri panimana ay ayante chau chau chau kati chate kati chata perro pampes ola sulo tasta la geben gausulo landa la geben tiempu chayna tiempu chayna sayari pauma gay gay inti chau chau kay santake/... (se repite todo el texto del canto) 
y como plato de fondo, la tradicional pataska, hecha de máiz pelado en ceniza, papas y carne bien picada.

Cuando terminan de bailar el chau-chau en la plaza, el alférez va invitando a la gente al almuerzo en la sede comunal.

Una vez que todos han almorzado, continúan con una ramada en el mismo lugar. En ella cada familia, por turno, va of reciendo vino o chicha a los presentes, mientras que bailan huainos y trotes, bailes a los que luego se añaden las cumbias.

Al igual que el día domingo, el lunes pasa a ser un día de fiesta. en el que la comunidad también participa la boda, la que es ofrecida por un nuevo alférez. Todos comen, bailan y se divierten.

Los días martes y miércoles los propietarios de terrenos, junto a sus familiares, parientes y compadres, limpian el canal que pasa por sus propiedades.

El martes lo hacen en la quebrada chica, que posee su fuente de agual propia, situada en el centro del pueblo.

El miércoles limpian en el sector Quito que es un ramal del canal matriz, a la entrada del pueblo.

Todos, propietarios y visitas, participan un almuerzo, pero esta vez a nivel familiar.

El día jueves la mayoría de los comuneros se reúnen para evaluar lo que fue la limpia de canales; además para elegir la nueva directiva comunal, de las asociaciones y de otros comités del pueblo.

Obviamente el ceremonial de la limpia de canales reúne una serie de elementos simbólicos. Cada rito tiene su significado especial, como, por ejemplo el uso de las chuspas con hojas de coca. que simbolizan el poder: el empleo de los cachos y látigos, que rellejan la altitoridad: Ios abrazos, cantos y perdones, que atañen a la renovación; cl baile del chatu-chau. que representa la fuerza del agua.

La condición ceremonial-simbólica se complementa con la funcionalidad de la faena misma de la mantención de un medio necesario para la subsistencia, lo que se efectúa una vez al año según las creencias prehispánicas de los miembros del grupo que habita en Caspana, quienes mantienen la convicción sobre los atributos mágicos de los espíritus que viven en el agua.

Agradezco a Catalina Terán y a Francisco Paniri, de Caspana, por sus informaciones sobre la cultura de su pueblo, y a mi esposo George Sarracino, por su apoyo durante la realización de este trabajo. 


\section{BiBLIOGRAFÍA}

Aldunate, Carlos y Victoria Castro. Las Chullpas de Toconce y su relación con el poblamiento altiplánico en el Loa Superior. Periodo Tardio. Santiago, Ediciones Kultrun.

Barón, Ana María. Excavación de un cementerio: sus potencialidades. Tesis para optar al título de Licenciada en Prehistoria y Arqucología. Depto. de Antropología. Santiago, 1979.

Barthel, Thomas. "Ein Frühlingsfest der Atacameños", Zeitschrift fïr Ethnologie. LXXXIV. $\mathrm{N}^{\circ} 1,1959$. pp. 25-45.

Délano, Priscilla. Aspectos socioeconómicos de una conumidal del Norte Grande: Caspana. Tesis Departamento Ciencias Sociológicas y Antropológicas. Santiago, 1982.

Isbell, Billie Jean. To defend ourselves: Ecology and Ritual in an Andean Village, Austin, University of Texas Press. 1978.

Lagos, Reinaldo, Emilio Mendoza y Nolberto Ampuero. La noche de los Abuelos. I Congreso lberoamericano de estudiosos del folklore, 1981.

Ochsenuis, Claudio. "Observaciones geológicas en la Puna de Atacama, Chile". Boletín de Prehistoria de Chile, N $\mathrm{N}^{\circ}$ 3-4. 1971. pp. 27-48.

Orellana, Mario. "Informe de la primera lase del proyecto arqueológico Río Salado". Antropología, Año III, $\mathrm{N}^{\circ}$ único, 1965, pp. 81-118.

Orellana, Mario. "Tipos Alfareros en la zona del Río Salado". Bolerín de Preluistorin de Chile, Año I, N* 1, 1968, pp. 3-32.

Serracino, George. "Creencias, Organización Social y Economía en Caspana Indígena. La limpia de canales". Actas I Congreso Chileno de Antropologia, 1985, pp. 398-410.

Tello, Julio y Próspero Miranda. Wallalo: Ceremonias gentilicias realizadas en la religión Cisa andina del Perú Central. Inka: No 1, 1923, pp. 475-549. 